\title{
Caso Clínico-Radiológico
}

\author{
NICOLÁS ROJAS D. ${ }^{1}$, ISOLDA BUDNIK O. ${ }^{1}$, TERESA PARAM S. ${ }^{2}$, BERNARDITA PACHECO V. ${ }^{3}$ \\ 1. Becado de Pediatría. Departamento de Pediatría. Escuela de Medicina. Universidad de los Andes. \\ 2. Médico Pediatra y Broncopulmonar infantil. Servicio de Pediatría Hospital Militar de La Reina. \\ Profesora Auxiliar Departamento de Pediatría. Escuela de Medicina. Universidad de los Andes. \\ 3. Médico Radiólogo. Servicio de Radiología Hospital Militar de La Reina.
}

\section{Historia Clínica}

Preescolar femenino de 2 años de edad, producto de primer embarazo normal, de 37 semanas, parto eutócico, peso de nacimiento: 3070 gramos, y talla $51 \mathrm{~cm}$, APGAR 8-9. Antecedentes mórbidos: 3 episodios de síndrome bronquial obstructivo leves a moderados, infección respiratoria por virus Influenza a los 5 meses de vida, síndrome febril a los 19 meses con Radiografía $(\mathrm{Rx})$ de tórax que mostró imágenes intersticiales en la base del pulmón derecho, e intolerancia a la lactosa en tratamiento con especialista. Vacunas del Programa Nacional de Inmunizaciones (PNI) al día, no tiene vacunas complementarias y asiste a sala cuna.

Cuadro actual de 15 días de evolución caracterizado por tos seca y fiebre intermitente hasta $38^{\circ} \mathrm{C}$, por lo que consulta en le servicio de urgencia. Al examen físico estaba hemodinamicamente estable, bien hidratada y perfundida, sin requerimientos de oxígeno y al examen pulmonar se ausculta murmullo pulmonar conservado sin ruidos agregados. Test pack viral fue negativo, hemograma con 19900 leucocitos, $64,5 \%$ polimorfonucleares, VHS $82 \mathrm{~mm} / \mathrm{s}$ y PCR 12,4 mg/dL. Se solicita $\mathrm{Rx}$ de tórax (figura 1).

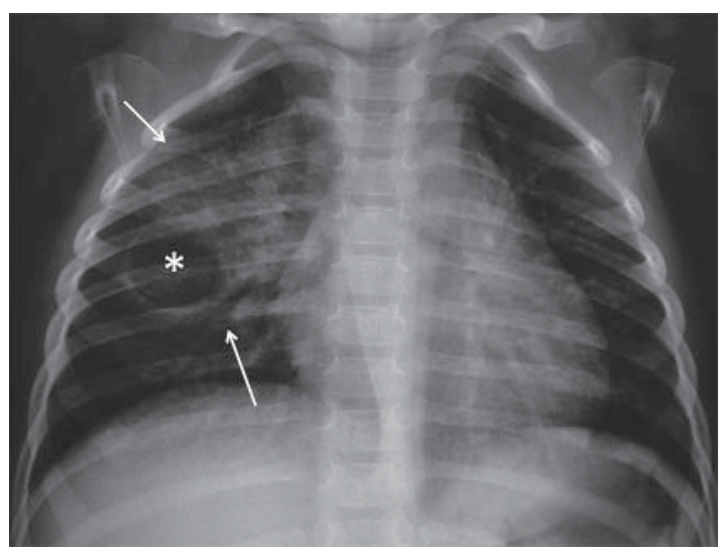

Figura 1.

\section{¿Cuál es su diagnóstico?}

Trabajo recibido el 18 de agosto de 2009, aceptado para publicación el 08 de enero de 2010.

Correspondencia a:

Nicolás Rojas del Río.

E-mail: rojasdelrio@gmail.com 


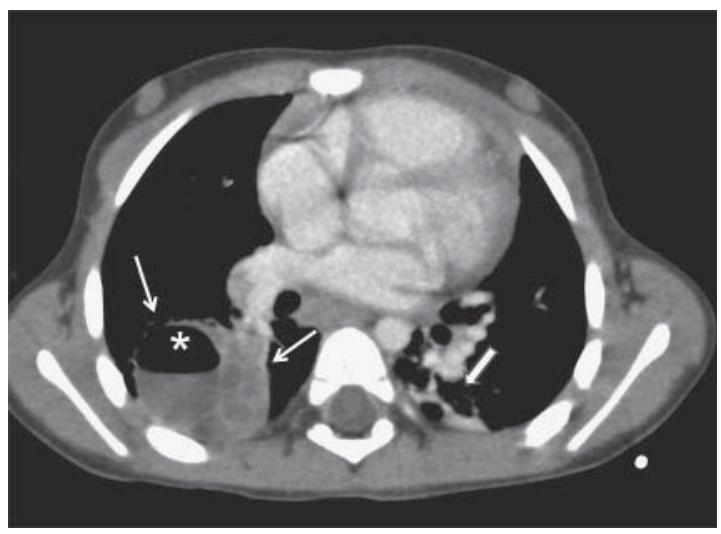

Figura 2a. Lesión multiquística en el segmento posterior del pulmón derecho (flechas). Nivel hidroaéreo en quiste de mayor tamaño $(*)$.

\section{Hallazgos Radiológicos}

La figura 1, muestra una opacidad parenquimatosa mal definida en el tercio medio del pulmón derecho (flecha), con una imagen de aspecto quístico y de paredes finas, de aproximadamente $2,5 \mathrm{~cm}$ de diámetro mayor en su borde inferior $(*)$.

La figura 2a, muestra TC de tórax en un corte axial, bajo el nivel de la carina, donde se identifica una lesión de aspecto multiquístico en el segmento posterior del pulmón derecho (flechas), con un nivel hidroaéreo en el interior del quiste de mayor tamaño $(*)$.

La figura $2 b$, muestra una TC en reconstrucción coronal, con mejor demostración de la extensión sagital de la lesión (flechas), con el quiste de mayor tamaño en el aspecto inferior (*). Se observan además áreas de atelectasia en ambos lóbulos inferiores (flechas gruesas).

El diagnóstico diferencial ante una lesión pulmonar de estas características y con la historia clínica de este paciente, debe incluir fundamentalmente una Malformación adenomatoídea quística congénita (MAQ). Otras consideraciones diagnósticas deben incluir la posibilidad de un secuestro pulmonar asociado a infección pulmonar recurrente, sin embargo, la mayoría de los secuestros pulmonares comprometen la base del pulmón y en todos ellos se identifica un vaso arterial aberrante con mayor

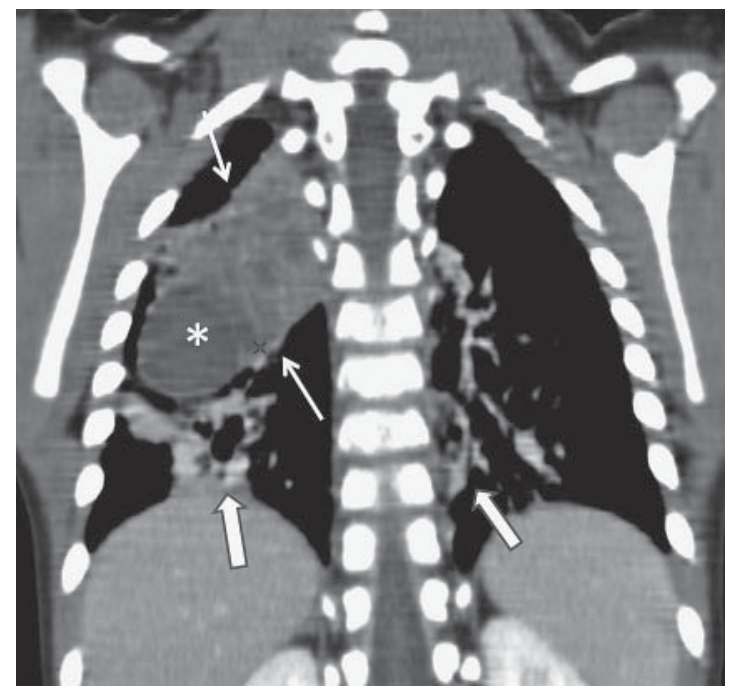

Figura 2b. Lesión multiquística en pulmón derecho. Áreas de atelectasia en lóbulos inferiores.

frecuencia naciendo de la aorta abdominal, que irriga directamente la lesión, lo que no ocurrió en este caso. La posibilidad de una neumonía necrotizante, de un abscesopulmonar o de una neumonía asociada a neumatocele son menos probables, por el aspecto de la lesión.

El paciente fue sometido a cirugía con resección de la lesión y el estudio histológico confirmó el diagnóstico. La evolución posterior fue satisfactoria.

\section{Diagnóstico}

Malformación adenomatoídea quística congénita.

\section{Discusión}

La malformación adenomatoídea quística congénita (MAQC) es una anomalía poco frecuente, que consiste en una proliferación anormal de elementos mesenquimáticos del pulmón, durante la etapa de maduración de estructuras bronquiolares normales en el desarrollo embrionario, lo que ocurre entre la $5^{\mathrm{a}}$ y $6^{a}$ semanas de gestación y persiste como una estructura no comunicada con la vía aérea normal. Con mayor frecuencia compromete sólo 
un lóbulo y afecta en forma similar a ambos sexos. La presentación clínica es variable y depende del tamaño de la lesión, de sus características morfológicas y la presencia de complicaciones, siendo la sobreinfección la complicación más frecuente. Cuando es de mayor tamaño, se puede manifestar en el período neonatal con distrés respiratorio, por efecto de masa. Sin embargo, un $50-60 \%$ de los pacientes no presenta síntomas al nacer y desarrolla posteriormente infecciones respiratorias recurrentes, como ocurrió en nuestro paciente, como resultado del aumento de las secreciones producidas por el tejido anormal y de la apertura de la lesión hacia la vía aérea. Por ser una anomalía localizada, característicamente las infecciones recurrentes ocurren siempre en la misma localización del pulmón, a diferencia de otras causas de de infecciones pulmonares recurrentes. En estos casos, el paciente presenta un cuadro clínico compatible con una neumopatía aguda y en la Rx de tórax se observa una opacidad pulmonar, consistente con una condensación neumónica, la que puede tener efecto de masa y niveles hidroaéreos en su interior. Característicamente, la sintomatología clínica regresa con el tratamiento antibiótico, sin embargo, la opacidad pulmonar persiste total o parcialmente en la Rx y es esto lo que debe hacer sospechar una anomalía pulmonar congénita subyacente. También puede manifestarse como un hallazgo incidental en una $\mathrm{Rx}$ de tórax, con aspecto de una opacidad pulmonar focal homogénea, parcialmente quística o puramente quística o hiperlúcida, con o sin efecto de masa sobre el pulmón subyacente. Hoy en día, muchas veces el diagnóstico puede ser prenatal, como hallazgo de una ultrasonografía obstétrica de rutina, donde el diagnóstico puede sospecharse desde las 20 semanas de edad gestacional, en especial cuando las lesiones presentan quistes de mayor tamaño. Este hallazgo es indicación de manejo del parto en un Centro que disponga de una Unidad de Cuidado Intensivo Neonatal. Se han descrito casos donde se observa mediante seguimiento ultrasonográfico, una regresión espontánea de la lesión a medida que progresa el embarazo, llegando incluso a su desaparición antes del nacimiento.
Se ha intentado clasificar esta patología, fundamentalmente según sus características morfológicas y la clasificación más utilizada ha sido la propuesta por Stocker en 1977, donde se dividen las lesiones en tres tipos de acuerdo a su morfología:

- Tipo I: Corresponde al 50\% de los casos y se manifiesta como un quiste único grande, o quistes múltiples, $>2 \mathrm{~cm}$ de diámetro. En la histología, se observa dilatación alveolar y escaso o mínimo componente adenomatoídeo. .

- Tipo II: Corresponde al 40 a 45\% de los casos.y consiste en múltiples quistes más pequeños, la mayoría $<1 \mathrm{~cm}$. Histológicamente se observan bronquíolos dilatados con transformación adenomatoídea. Se puede asociar a otras malformaciones congénitas, generalmente genitourinarias o gastrointestinales.

- Tipo III: Es el tipo menos frecuente y corresponde a menos del 5\% de los casos. Se manifiesta como una masa compleja, pero fundamentalmente sólida, compuesta por tejido adenomatoso en la histología. Este tipo se ha asociado a un mal pronóstico.

De una forma más simple, Adzick propuso en 1987 clasificarla en dos tipos:

- Forma macroquística, con lesiones iguales o mayores que $5 \mathrm{~mm}$.

- Forma microquística, con lesiones menores a $5 \mathrm{~mm}$.

En el caso de nuestro paciente, correspondería a una forma mixta tipo I/II según la Clasificación de Stocker.

La MAQC puede asociarse a secuestro pulmonar, si bien esto es un hecho poco frecuente.

Se ha descrito la eventual malignización de las lesiones, hecho que se ha reportado hacia la tercera década de la vida, por lo que se ha recomendado la resección quirúrgica de todas estas lesiones, al margen del cuadro clínico. Sin embargo, si las lesiones son pequeñas y constituyen un hallazgo radiológico en pacientes asintomáticos, algunos autores recomiendan la observación clínica y control radiológico.

Dentro del estudio de imágenes, la Rx de tórax es en la mayoría de los casos, el método 
diagnóstico inicial y es el que se utiliza para observar la evolución de las lesiones. Sin embargo, la Tomografía computarizada (TC), es la que permite una adecuada demostración anatómica y delimitación de las lesiones, además de una excelente demostración de su vascularización, previo a la cirugía, lo que es especialmente importante ante la eventual asociación con secuestro pulmonar. Es importante destacar que este método utiliza radiación ionizante y debe utilizarse con precaución. Ante la sospecha de MAQC en el caso de una infección pulmonar recurrente, la TC debe hacerse una vez que el cuadro agudo esté clínicamente resuelto e idealmente después de dos semanas y estando el paciente asintomático. De no ser así, puede ser difícil distinguir entre lesiones parenquimatosas agudas y una MACQ subyacente. La Rx y TC de tórax son en la gran mayoría de los casos, suficientes para el diagnóstico y para decidir la conducta terapéutica. Otras técnicas, como la Resonancia Magnética (RM) son raramente utilizadas en estos casos.

El tratamiento de elección es quirúrgico, aún cuando no haya compromiso de la función pulmonar. Éste está indicado para evitar complicaciones, en especial la sobreinfección y con menor frecuencia, neumotórax por rotura de la lesión hacia el espacio pleural y eventual transformación maligna. Sin embargo, como ya fue mencionado, si las lesiones son pequeñas y constituyen un hallazgo radiológico en pacientes asintomáticos, algunos autores recomiendan la observación clínica y control radiológico.

La cirugía mínimamente invasiva y videotoracoscopia han demostrado un buen rendimiento en el manejo de estas lesiones.

\section{Referencias}

1.- Landing BH, Dixon LG: Congenital malformations and genetic disorders of the respiratory tract (larynx, trachea, bronchi, and lungs). Am Rev Respir Dis 1979; 120: 151.

2.- Kravitz RM: Congenital malformations of the lung. Pediatr Clin North Am 1994; 41: 453.

3.- Kim WS, Lee KS, Kim IO, et al: Congenital cystic adenomatoid malformation of the lung: CT-pathologic correlation. AJR Am J Roentgenol 1997; 168: 47.

4.- $\quad$ Stocker JT, Madewell JE, Drake RM: Congenital cystic adenomatoid malformation of the lung. Classification and morphologic spectrum. Hum Pathol 1977; 8: 15571.

5.- Adzick NS, Harrison MR, Crombleholme TM, Flake $A W$, Howell LJ: Fetal lung lesions: management and outcome. Am J Obstet Gynecol 1998; 179 (4): 884-9.

6.- Zúniga S, Sánchez I: Malformaciones broncopulmonares. En Sánchez I., Prado F. ed. Enfoque clínico de las enfermedades respiratorias del niño, $1^{\text {a }}$ Edición. Santiago: Ediciones Universidad Católica de Chile, 2007; 375-7.

7.- MacGillivray TE, Harrison MR, Goldstein RB, Adzick NS: Disappearing fetal lung lesions. J Pediatr Surg 1993; 28: 1321-4.

8.- Marshall $K W$, Blane CE, Teitelbaum DH, van Leeuwen, $K$ : Congenital Cystic Adenomatoid Malformation: Impact of Prenatal Diagnosis and Changing Strategies in the Treatment of the Asymptomatic Patient. Am J Roentgenol 2000; 175: 1551-4.

9.- Aziz, D, Langer, JC, Tuuha SE, et al: Perinatally diagnosed asymptomatic congenital cystic adenomatoid malformation: to resect or not? J Pediatr Surg 2004; 39: 329.

10.- Butterworth SA, Blair GK: Postnatal spontaneous resolution of congenital cystic adenomatoid malformations. J Pediatr Surg 2005; 40: 832. 